\title{
TINEREŢEA SUFLETEASCĂ ŞI IMPORTANŢA EI ÎN GÂNDIREA LUI NICHIFOR CRAINIC
}

Maxim (Iuliu-Marius) Morariu*

Emanuel Ioan Căşvean**

\begin{abstract}
The youth of mind and its importance in the taught of Nichifor Crainic. The youth of mind is important also for the patristic Theology, for the later one and for the Philosophy and poetry. In the Romanian Theology, one important author who shows the importance of the youth of mind is Nichifor Crainic. In his poems, his philocophical works or in his theological articles, the author speaks about. In this study, we will try to investigate his works and to show the most important caracteristics and the particularities of this subject in Nichifor Crainic's work. We will research the poetry published during his life in the pages of the books or of rewievs as Gândirea (The taught), Ramuri (Branches), Transilvania and s. o., but also the poetry anthologised posthumously by some of the researchers of his works, the philosophical studies and articles.
\end{abstract}

Keywords: The Chalice song, mystique, politics, orthodoxy, etnocracy.

\section{Introducere}

Tinereţea constituie un element important al teologiei mai vechi sau mai noi. Sfinţii Părinţi, au scris despre ea, interpretând cuvintele Mântuitorului, care a spus: Lăsaţi copiii să vină la Mine că a unora ca aceştia este impărăţia cerurilor (Mc. 10, 14). Aceste cuvinte relevă însă două moduri de manifestare ale tinereţii, diferite, ce nu se exclud reciproc, respectiv tinereţea trupească, condiţionată de vârstă şi cea sufletească. Cele două pot fi concomitente, fără ca acest fapt să fie însă

* Masters student, Faculty of Orthodox Theology at „Babeş-Bolyai” University, Cluj-Napoca, Romania.

** PhD Candidate, Faculty of Orthodox Theology at „Babeş-Bolyai” University, Cluj-Napoca, Romania. 
obligatoriu. Astfel, un om poate fi tânăr trupeşte, fără a mai avea însă acea prospeţime sufletească care să-l definească şi din acest punct de vedere ca fiind la fel ${ }^{1}$, iar un om bătrân cu vârsta poate avea această tinerețe sufletească care e considerată de către mulţi dintre Sfinţii Părinţi ca fiind o virtute.

Conştient de importanţa tinereţii sufleteşti, controversatul, dar importantul filosof şi teolog interbelic Nichifor Crainic ${ }^{2} \mathrm{~s}$-a preocupat şi el de acest subiect. Deşi nu a constituit o temă predilectă a cercetării lui, adesea aspecte privitoare la acest subiect fiind mai degrabă sugerate decât prezentate în mod clar, el oferă totuşi informaţii importante cu privire la acest aspect, conturând o viziune clară şi adesea argumentată cu privire la importanţa lui. Utilizând revelaţia, singura sursă $a$ dogmei, după exprimarea părintelui Justin Popovici ${ }^{3}$, dar şi elemente cu valoare literară, Crainic oferă o imagine interesantă asupra acestui aspect.

${ }^{1}$ Romanul lui Oscar Wilde, Portretul lui Dorian Gray ilustrează într-un mod interesant această situaţie. Cf. Oscar Wilde, The picture of Dorian Gray, Oxford, Oxford University Press, 1981.

${ }^{2}$ Pentru mai multe informaţii biografice despre el, a se vedea: Geta Marcela Pârvulescu, Nichifor Crainic- monografie, Deva, Edit. Emia, 2010; Stelian Spânu, Nichifor Crainic - lumini și umbre. O biografie, București, Edit. Saeculum Vizual, 2013; Răzvan Codrescu, Nichifor Crainic - schiță de portret, în „Tabor”, III (2010), nr. 10, p. 81-86; Laura Bădescu, Observații asupra autocenzurii în totalitarism. Cazul Nichifor Crainic, în „Tabor”, III (2010), nr. 10, p. 71-76; Eugen Lovinescu, Istoria literaturii române contemporane (1900-1937), București, Edit. Librăriei Socec, 1937, p. 92-93; Elena-Irina Ancuța, Nichifor Crainic - teolog și imnolog al neamului românesc, în Studii de știință și cultură, V (2009), nr. 4 (19), p. 50; Mihaela Albu, Dialogul științăareligie oglindit în literatura română (poezia Gândirii: intre încifrare şi revelație), în „Studii de știință și cultură”, V (2009), nr. 4 (19), p. 90.

${ }_{3}^{3}$ Justin Popovitch, Philosophie Orthodoxe de la Verite - Dogmatique de l'Eglise Orthodoxe, trad. Jean-Louis Palierne, Tome Premier, col. „La Lumiere du Thabor", Lausanne, Editions L'Age de L'Homme, 1993, p. 85. 


\section{Tinerețea sufletească şi importanța ei în gândirea lui Nichifor Crainic}

În poemul Miserere Domine, el vorbeşte despre importanţa tinereţii sufleteşti prin intermediul unei imagini de contrast ${ }^{4}$. Astfel, sugerând batrânețea sufletească şi starea de pustiire pe care o aduce ea şi regretând modul în care, petrecerea nepotrivită a tinereţii i-a adus-o, el cere lui Dumnezeu să intervină şi să-i restituie bucuria de a se resimţi din nou tânăr în sufletul său. Recâş̧igarea tinereţii sufleteşti, a restituirii ei odată ce a fost pierdută, prin intermediul lucrării harice este caracteristică de altfel întregii pleiade de gânditori ortodocşi, însă modul în care este ea exprimată în versurile lui Crainic e unul special şi constituie o particularitate a gândirii sale privitoare la acest subiect.

În alt poem, al cărui titlu conţine referiri la Evanghelie, sugerează, ea adevărat, într-un mod mai voalat decât cea dintâi, aceeaşi idee, a restituirii tinereţii sufleteşti prin har. Autorul merge însă de această dată mai departe, arătând mijlocul prin care se poate redobândi această tinereţe, respectiv a sufletului. Metafore precum setea de mai bine, pigmentează şi ele peisajul şi contribuie la crearea unei cromatici poetice foarte reuşite şi la reliefarea acestui important aspect ${ }^{5}$.

${ }^{4}$ „O, Crist, mi-aduc la tine, obosit, / Și sâgnerat adânc de-atâtea rele, Miserere, / Tremurătorul suflet părăsit / În negurile desnădejdii mele. / În veci dorind și-n veci nemulțumit, / M-au amânat mereu tot mai departe / Cărările pe unde m-au momit / Ispitele iluziei deșarte. / O dulce Crist, și cum s-ar relfecta / Un crin deargint pe-a apei unduiere, / Apleacă luminoasă fața ta / Pe-a sufletului meu nemângâiere. / Și-nalță iar din tristul meu pustiu / Speranțele și-avânturile sfinte, / Cum se ridică-n cerul azuriu / Un stol de porumbei de pe morminte”. Nichifor Crainic, Darurile pământului, poezii, ed. III, București, Edit. Cartea Românească, 1929, p. 157-158.

${ }^{5}$ Redăm mai jos textul poeziei: „O, sângele ce-o clocoti / Într-a strădaniei dogoare / Urcând pe Om în infinit / Prin tine îndumnezeit / Durere Creatoare! / Golgota sângeră mereu / Din umbra veacurilor duse / Și-ai fost cu-atât mai Dumnezeu / Cu cât ai suferit mai greu / Pe crucea ta, Iisuse. / Întreg pământu-mpurpurând, / Golgota sângeră-n osândă / Din neam în neam, dar rând pe rând, / Noi binecuvântăm, gemând, / Golgota sângerândă / Tu care pretutindeni ești / Şi totdeauna deopotrivă, / În inimi te destăinuiești /Mai viu când ne împărtășești /Durerea-ţi milostivă. / Ne torni pe cupa cu venin / Adânca sete de mai bine / Și- 
Conştient că oricare ar fi alcătuirea nouă a lumii, spiritul nu va dispărea ${ }^{6}$, Crainic militează pentru conservarea unui tonus pozitiv al acestuia atât în opera sa poetică, cât şi în cea filosofică. Timpurile pe care le trăieşte nu reprezintă altceva decât o vreme a tineretului ${ }^{7}$, fapt pentru care, el militează pentru buna călăuzire a generaţiilor viitoare.

Într-o creaţie ce îmbină ludicul cu literatura reliefând aspecte ale cadrului temporal al copilăriei, autorul se ocupă de o astfel de educaţie, oferind informaţii teologice importante cu privire la Euharistie şi la rolul ei în conservarea tinereţii sufleteşti ${ }^{8}$. Abundenţa imagistică şi modul degajat în care descrie anumite aspecte legate de fundamentele teologiei răsăritene reprezintă apodictic calităţi stilistice ale creaţiei lui.

adii pe omenescul chin / Dumnezeiescul tău suspin / Ca să ne sui cu tine”. Idem, Cântec Evanghelic, în „Neamul Românesc”, XIII (1918), nr. 17, p. 1; Idem, Țara de peste veac. Poezii antume (1916-1944), ed. Ioan Cracă, București, Edit. Eminescu, 1997, p. 153-154.

${ }^{6}$ Idem, Pro Domo, în „Gândirea”, IV (1925), nr. 6, p. 161-163.

${ }^{7}$ Idem, Tineretul și creștinismul, în „Gândirea”, XIII (1934), nr. 3, p. 65-73. Cf. Idem, Tineri și bătrâni, în „Gândirea”, XII (1932), nr. 4, p. 192.

8 „Când holda tăiată de seceri fu gata/ Bunicul și tata/ Lăsară o chită de spice-n picioare/ Legând-o cucernic cu fir de cicoare;/ Iar spicele-n soare sclipeau mătăsos/ Să-nchipuie barba Domnului Hristos./ Când pâine-n cuptor semăna cu arama/ Bunica și mama/ Scoțându-o sfielnic cu semnele Crucii,/ Purtau parcă moaște cinstite și lucii/ Că pâinea, dând abur, cu dulce miros,/ Părea că e fața lui Domnul Cristos./ Și iată, potirul la gură te-aduce,/ Iisuse Cristoase, tu jertfă pe cruce,/ Hrănește-mă, mamă de sfânt Dumnezeu./ Ca bobul în spice și mustu-n ciorchine/ Ești totul în toate şi toate prin tine,/ Tu pâinea de-a pururi a neamului meu./ Din coarda de viță ce-nfăşură crama/ Bunica și mama/ Mi-au rupt un ciorchine, spunându-mi povestea,/ Copile, grăiră broboanele-acestea/ Sânt lacrimi de mamă vărsate prinos/ La casnele Domnului nostru Hristos./ Și iată potirul la gură te-aduce,/ Iisuse Cristoase, tu jertfă pe Cruce;/ Adapă-mă, sevă de sfânt Dumnezeu./ Ca bobul în spice și mustu-n ciorchine/ Ești totul în toate și toate prin tine,/ Tu vinul de-a pururi a neamului meu./ Podgorii bogate și lanuri mănoase,/ Pământul acesta, Iisuse Cristoase,/ E raiul în care ne-a vrut Dumnezeu./ Priveștete-n vie și vezi-te-n grâne/ Și sângeră-n struguri și frânge-te-n pâine,/ Tu viața dea pururi a neamului meu". Ioana Cistelecan, Antologia poeziei carcerale, ClujNapoca, Edit. Eikon, 2006, pp. 63-64; Ion Buzași, Poezia religioasă românească, ed. a II-a, Cluj-Napoca, Edit. Dacia XXI, 2011, p. 153. 


\section{$15^{\text {th }}$ International Symposium on Science, Theology and Arts}

Din punct de vedere teologic, trebuie spus însă şi faptul că poemul denotă pe de-o parte tinerețea sufletească a autorului, căci numai un om ce posedă o astfel de tinereţe putea scrie astfel. Pe de altă parte, ea este un manifest creștin pentru tinerețea sufletească ce nu poate fi păstrată sau regăsită decât prin intermediul Euharistiei, care asigură întâlnirea cu Hristos şi crează premisele pentru comuniunea perpetuă cu El.

Cursurile sale de mistică, lucrări ce se plasează la interferenţa dintre teologie şi filosofie sunt de asemenea importante pentru acest subiect. Faptul că autorul vorbeşte despre urcuşul mistic şi despre tainele de iniţiere, valorificând concepţia Sfântului Nicolae Cabasila cu privire la modul în care Botezul devine Taina purificării ${ }^{9}$, e important căci, confirmă cele afirmate anterior de el în cadrul scrierilor poetice, cu privire la posibilitatea conservării sau recâştigării tinereţii sufleteşti prin intermediul lucrării harului.

Ancorat puternic în concepţia creştină $^{10}$, el militează şi aici pentru importanţa Euharistiei şi vorbeşte despre rolul ei pentru conservarea tinereţii spirituale:

„De aceea, Taina sfintei Euharistii e sâmburele de foc al cultului ortodox. Ea e misterul prefacerii naturii create în natură divină. Vinul și apa prefăcutee în sângele Mântuitorului, pâinea prefăcută în trupul Lui constituie hrana fără prihană , care transformă natura creată în natură divină. Esența practică și reală a religiei noastre e acest praznic misterios în care Hristos, carne adevărată și sânge adevărat, se împarte mâncare credincioșilor. Iar dacă sângele și vinul păstrează aspectul de vin și

9 „Nicolae Cabasila reliefează în mod cu totul deosebit, care sunt de la începutul creștinismului Tanele de inițiere în viața creștină: Botezul, Mirungerea și Euharistia ... Botezul e prin excelență Taina purificării, Mirungerea, Taina Iluminării, iar Euharistia, Taina sfințirii sau a desăvârșirii”. Idem, Cursurile de mistică, ed. Ioan Ică jr, Sibiu, Edit. Deisis, 2010, p. 251.

${ }^{10}$ După cum ţin să arate şi criticii literari. Iată, de exemplu, ce spune Ovid Crohmălniceanu: ,pledoaria cea mai înfocată pentru o poezie hrănită de un puternic sentiment religios, care să se acorde chiar cu dogma credinței creștine răsăritene, a susținut-o Nichifor Crainic". Ov. S. Crohmălniceanu, Literatura română intre cele două războaie mondiale, vol. II, București, Edit. Minerva, 1974, p. 311. 
pâine, Ioan Damaschinul, sprijinindu-se pe Grigore al Nyssei, lămurește că aceasta e o concesie pe care Dumnezeu o face neputinței omenești’’11.

Euharistia aduce cu ea asimilarea naturii noastre în Hristos, după cum el însuşi ţine să arate în cadrul tratatului său: Hrana euharistică, obținută prin prefacerea misterioasă a elementelor din natura creată are ca scop nu de a asimila pe Hristos naturii noastre, ci de a asimila natura noastră lui Hristos ${ }^{12}$.

Creştinismul lui Crainic, care, după cum arată părintele Dumitru Stăniloae: nu se reduce la perceptele teologice învățate din Evanghelie și din cărți, ci e un creștinism manifestat în practicile și datinile poporului român, care și-a păstrat autenticitatea lui neslăbită şi nealterată în satele noastre ${ }^{13}$, are între temele importante şi acest aspect al tinereţii sufleteşti, utilă pentru demersul urcuşului spre înviere ce trebuie să caracterizeze viaţa fiecărui creştin.

${ }_{11}^{11}$ Ibidem, p. 275-276.

${ }^{12}$ Ibidem, p. 276. În alt loc, vorbind despre recrearea duhovnicească a omului prin Trupul şi Sângele îndumnezeit al lui Hristos, el spune:

„Modelul biblic al unirii desăvârșitoare cu Dumnezeu (tema prelegerii XII) este Schimbarea la Față a Mântuitorului pe Tabor, lumina taborică, lumina anticipată a vieții eshatologice, fiind obiectul și țelul ultim al spiritualității ortodoxe. Caracterul transformant al acestei uniri îndumnezeitoare este însă anticipat sacramental în miracolul Euharistiei, Taina Tainelor. În Împărtășire noi nu $\hat{\imath}$ asimilăm pe Hristos, ci Hristos ne asimilează pe noi, actualizând îndumenzeirea noastră ca înfiere supranaturală, finalizând recrearea duhovnicească a omului prin Trupul și Sângele Său îndumnezeite”.

Ioan Ică jr., Nichifor Crainic și redescoperirea misticii în Ortodoxie în prima jumătate a secolului XX, în Nichifor Crainic, Cursurile de mistică, Sibiu, Edit. Deisis, 2010, p. 52. Cf. Nichifor Crainic, Sfințenia - implinierea umanului (curs de teologie mistică), ed. Teodosie Paraschiv, col. „Teologie și Spiritualitate”, nr. 2, Iași, Edit. Mitropoliei Moldovei și Bucovinei, 1993, p. 169.

${ }^{13}$ Dumitru Stăniloae, Poezia creștină a lui Nichifor Crainic, în Nichifor Crainic, Șoim peste prăpastie. Versuri inedite create în temnițele Aiudului, ed. Nedic Lemnaru, Bucureşti, Edit. Roza Vânturilor, 1990, p. 7. 


\section{$15^{\text {th }}$ International Symposium on Science, Theology and Arts}

De altfel, tinereţea se regăseşte până şi în scrisul său memorialistic. În însemnările în care îşi povesteşte peregrinările prin ţară şi fuga din faţa comuniştilor, cenzurate şi pregătite spre a fi publicate încă din timpul regimului ${ }^{14}$, fără succes însă, se regăsesc adesea descrise scene în care interacţionează cu copii şi lasă să se întrevadă pătrunderea acelei îmbâniri a sufletului în inima lui Crainic. Tuşele adesea nostalgice, ce pot să îl ducă pe cititor cu gândul fie la pierderea petrecută atunci, în momentul petrecerii evenimentelor, a acestei tinereţi, fie mai târziu, în momentul scrierii, fapt ce pare mai plauzibil, relevă dorinţa lui de a recâş̧iga tinereţea şi prospeţimea sufletească pe care o avusese înainte ${ }^{15}$ şi regretul generat de pierderea lor.

\section{Concluzii}

Aşadar, după cum se poate vedea şi din paginile cercetării de faţă, tinereţea sufletească reprezintă un element important atât pentru teologia contemporană, cât şi pentru gândirea filosofico-poetică şi teologică a lui Nichifor Crainic. Parte a itinerarului duhovnicesc şi element important a progresului pe calea mântuirii, aceasta poate fi pierdută şi apoi recâştigată prin intermediul lucrării harului în sufletul omului. Poeziile autorului, scrierile sale filosfice, cele religioase, dar şi cele memorialistice, vorbesc despre ea şi despre modul în care poate fi ea pierdută şi recâş̧igată. Autorul însuşi o pierde în temniţele comuniste, în urma compromisurilor pe care le face. Faptul în sine îi generează stări de tristeţe şi de supărare şi îl determină să lupte pentru recâş̧igarea ei. Un element important în cadrul acestei recâş̧igări îl reprezintă, apodictic, Euharistia care conferă cadrul întâlnirii cu Dumnezeu şi a redobândirii sau a conservării ei.

${ }^{14}$ Cf. Nichifor Crainic, Zile albe, zile negre. Memorii, vol. 1, ed. Nedic Lemnaru, București, Edit. Gândirea, 1991.

${ }^{15}$ Şi pe care, unii dintre scriitorii de literatură i-o atribuie, în operele lor, şi mai târziu. Cf. Virgil Gheorghiu, Condotiera, trad. Georgiana Matei, Cluj-Napoca, Edit. Renaşterea, 2011. Aici autorul îi dedică personajul poetului şi îl descrie în culori de-a dreptul encomiastice. 


\section{Bibliografie}

1. Albu, Mihaela, Dialogul știință-religie oglindit în literatura română (poezia Gândirii: intre încifrare și revelație), în Studii de știință și cultură, V (2009), nr. 4 (19).

2. Ancuța, Elena-Irina, Nichifor Crainic - teolog și imnolog al neamului românesc, în „Studii de știință și cultură", V (2009), nr. 4 (19).

3. Bădescu, Laura, Observații asupra autocenzurii în totalitarism. Cazul Nichifor Crainic, în „Tabor", III (2010), nr. 10.

4. Buzași, Ion, Poezia religioasă româneascăa, Ediția a II-a, Cluj-Napoca, Edit. Dacia XXI, 2011.

5. Cistelecan, Ioana, Antologia poeziei carcerale, Cluj-Napoca, Edit. Eikon, 2006.

6. Codrescu, Răzvan, Nichifor Crainic - schiță de portret, în "Tabor", III (2010), nr. 10.

7. Crainic, Nichifor, Cântec Evanghelic, în „Neamul Românesc", XIII (1918), nr. 17.

8. Idem, Cursurile de mistică, ed. Ioan Ică jr, Sibiu, Edit. Deisis, 2010.

9. Idem, Darurile pământului, poezii, Editia a III-a, București, Edit. Cartea Românească, 1929.

10. Idem, Pro Domo, în „Gândirea", IV (1925), nr. 6.

11. Idem, Sfințenia - implinierea umanului (curs de teologie mistică), ed. Teodosie Paraschiv, col. „Teologie și Spiritualitate”, Nr. 2, Edit. Mitropoliei Moldovei și Bucovinei, Iași, 1993.

12. Idem, Tineretul și creștinismul, în „Gândirea", XIII (1934), nr. 3.

13. Idem, Tineri și bătrâni, în „Gândirea", XII (1932), nr. 4.

14. Idem, Țara de peste veac. Poezii antume (1916-1944), ed. Ioan Cracă, București, Edit. Eminescu, 1997.

15. Idem, Zile albe, zile negre. Memorii, vol. 1, ed. Nedic Lemnaru, București, Edit. Gândirea, 1991.

16. Crohmălniceanu, Ov. S., Literatura română între cele două războaie mondiale, vol. II, București, Edit. Minerva, 1974.

17. Gheorghiu, Virgil, Condotiera, trad. Georgiana Matei, Cluj-Napoca, Edit. Renaşterea, 2011.

18. Ică, Ioan jr., Nichifor Crainic și redescoperirea misticii în Ortodoxie în prima jumătate a secolului $X X$, în Nichifor Crainic, „Cursurile de mistică", Sibiu, Edit. Deisis, 2010.

19. Lovinescu, Eugen, Istoria literaturii române contemporane (1900-1937), București, Edit. Librăriei Socec, 1937.

20. Pârvulescu, Geta Marcela, Nichifor Crainic- monografie, Deva, Edit. Emia, 2010. 
21. Popovitch, Justin, Philosophie Orthodoxe de la Verite - Dogmatique de l'Eglise Orthodoxe, trad. Jean-Louis Palierne, Tome Premier, col. „La Lumiere du Thabor", Lausanne, Editions L'Age de L'Homme. 1993.

22. Spânu, Stelian, Nichifor Crainic - lumini și umbre. O biografie, București, Edit. Saeculum Vizual, 2013.

23. Stăniloae, Dumitru, Poezia creștină a lui Nichifor Crainic, în Nichifor Crainic, „Şoim peste prăpastie. Versuri inedite create în temnițele Aiudului", ed. Nedic Lemnaru, Bucureşti, Edit. Roza Vânturilor, 1990.

24. Wilde, Oscar, The picture of Dorian Gray, Oxford, Oxford University Press, 1981. 